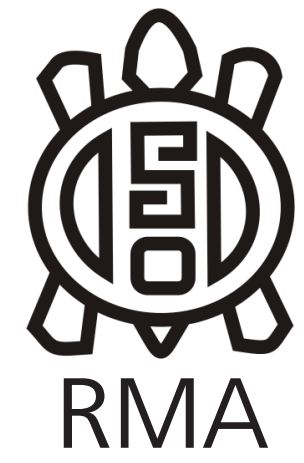

Arqueología

\title{
Una primera aproximación a las prácticas funerarias en los valles orientales del norte de Salta, Argentina
}

\author{
A first approach to funerary practices in the eastern valleys of northern \\ Salta, Argentina
}

\begin{abstract}
Beatriz N. Ventura* y María Soledad Gheggi**
${ }^{*}$ CONICET/Instituto de Arqueología. Facultad de Filosofía y Letras, Universidad de Buenos Aires.Email:beatrizventura2006@yahoo.com.ar ** CONICET/Centro Regional de Investigaciones y Transferencia Tecnológica La Rioja, Gob. de La Rioja, UNLar, UNCa, SEGEMAR. Email: solegheggi@gmail.com
\end{abstract}

\begin{abstract}
Resumen
En este trabajo se presentan los resultados del rescate de dos inhumaciones conteniendo restos humanos en situación de riesgo en Pueblo Viejo de Rodeo Colorado (PVRC), en el Departamento de Iruya, Salta. El análisis incluyó el estudio bioarqueológico de los restos y de las distintas formas de entierro registradas en los valles orientales del norte de Salta sobre la base de investigaciones previas. Presentamos los primeros fechados radiocarbónicos de PVRC y comparamos las formas de entierro y cronología con otros sitios de la región y extra-regionales, principalmente con la Quebrada de Humahuaca. Los entierros registrados pueden ser incorporados dentro de las prácticas funerarias conocidas para la región, aunque uno de ellos es novedoso ya que corresponde al entierro en urna de un cráneo de adulto. Referimos a la necesidad de trabajar junto con las comunidades locales, principalmente en los aspectos en los que tratamos con restos humanos en nuestras investigaciones.
\end{abstract}

Palabras clave: Tratamientos mortuorios; Prácticas funerarias; Cronología; Valles orientales; Salta.

\begin{abstract}
The preliminary results of our work with two human burials that were at risk at Pueblo Viejo de Rodeo Colorado (PVRC) site at Departamento de Iruya, Salta, are presented. They include results from bioarchaeological studies, as well as from the analysis of the different burial practices from the eastern valleys of northern Salta. In addition, results from previous research on these valleys are also considered. The first radiocarbon dates for PVRC and a comparison of burial methods and chronology with other sites from this and other regions, particularly the Quebrada de Humahuaca, are presented. Most cases fit into known funerary practices for the region, but the burial of an adult skull inside an urn is new. We refer to the need of working together with the local communities, especially when dealing with human remains.
\end{abstract}

Keywords: Mortuary remains; Burial practices; Chronology; Eastern Valleys; Salta.

Los contextos funerarios son una fuente inagotable de datos que permiten a la arqueología conocer diversos aspectos de las sociedades y de sus poblaciones (Cocilovo y Costa-Junqueira, 2001; Dillehay, 1995; Cocilovo y Varela, 2010; Shimada y Fitzsimmons, 2015; Verano, 2008, entre otros). En los Andes, uno de los aspectos importantes de las prácticas funerarias es que, a pesar de su gran diversidad, los muertos forman parte de la vida de los vivos, tanto en el ámbito de lo cotidiano (por ejemplo, en los entierros bajo los pisos de viviendas), como en el ámbito ceremonial (capacochas, exhibición de fardos de difuntos, día de los muertos). En este sentido, las almas de los difuntos son protectoras, consejeras y mensajeras (Aláez García, 2001; Avenburg y Talelis, 2015; Bascopé Caero, 2001).
En el Noroeste argentino (NOA) la antropología biológica ha aportado nuevos datos sobre sus poblaciones y sobre sus prácticas funerarias a través de investigaciones llevadas a cabo en la Puna, Quebrada de Humahuaca, valles Calchaquíes y en las tierras bajas orientales. En los últimos años se ha avanzado en tópicos como la dieta y patrones de consumo a lo largo del tiempo, dinámicas y movimientos poblacionales a partir de isótopos y marcadores genéticos, el estudio de trauma óseo vinculado con violencia y las prácticas funerarias en el marco de paisajes socialmente construidos (Baffi y Seldes, 2012; Gheggi y V.Seldes, 2012; Gheggi et al., 2018; Killian Galván, 2018; Killian Galván et al., 2021; Mendonça et al., 2012; Ortíz y Seldes, 2007; Seldes y Gheggi, 2014, entre otros). 
En los valles orientales del norte de Salta (Argentina), las investigaciones arqueológicas han mostrado diversas formas en el tratamiento para disponer a los muertos. En las Selvas pedemontanas, en la confluencia de los ríos San Francisco y Bermejo, registramos en Manuel Elordi 1 y en El Talar cementerios con entierros directos en tierra y de adultos en urnas, correspondientes al inicio del segundo milenio (Ventura, 1999). Mientras que en los valles ubicados al Este de las Serranías de Santa Victoria (Cordillera Oriental), en la década de 1930 Salvador Debenedetti, Eduardo Casanova (1933-35) y Fernando Márquez Miranda $(1937,1939)$ detectaron en sus excavaciones distintas formas de entierros humanos.

En este trabajo realizamos una síntesis de las formas de inhumar a los muertos registradas por esos investigadores en los valles de Iruya, Nazareno y Bacoya. Luego, presentamos los datos de un par de rescates arqueológicos que llevamos a cabo en el sitio Pueblo Viejo de Rodeo Colorado (PVRC) en el Departamento de Iruya, debidos al hallazgo de restos humanos en posición de riesgo, ya que algunos aparecían en superficie. Los restos humanos recuperados fueron analizados, realizándose sobre uno de ellos un fechado radiocarbónico. La necesidad de este tipo de metodología de trabajo expeditivo se debe a la constante y rápida destrucción que está sufriendo en los últimos años este sitio, aunque su deterioro tiene larga data. Por ello, consideramos apropiada la presentación de estos datos y las correspondientes propuestas sobre su cronología, aportando otras dos nuevas dataciones radiocarbónicas. Finalmente, incluimos un breve análisis de los distintos tipos de entierros registrados en estos valles orientales y su relación con la Quebrada de Humahuaca. Consideramos dentro de la arqueología mortuoria aquellos enfoques que analizan la relación ancestro-descendiente, en el sentido de que los muertos mantienen una activa vida social, juegan un papel e intervienen en la estructuración de la vida de los vivos (Buikstra, 1995; Parker Pearson, 1999; Rakita, 2001; Sillar, 1992, entre otros).

\section{Antecedentes}

Las primeras excavaciones arqueológicas en el valle de Iruya, al oriente de las Serranías de Santa Victoria, fueron llevadas a cabo en la década de 1930 por Casanova (1930) en Cerro Morado y por Debenedetti y Casanova (1933-35) en Titiconte. Entre 1933 y 1938 Márquez Miranda (1934, 1937, 1939, 1941), con un objetivo regional, realizó cuatro expediciones a los valles de Iruya, Bacoya y Nazareno excavando en una docena de sitios arqueológicos, principalmente asentamientos residenciales (Figura 1). Los materiales de esas expediciones provienen mayormente de las estructuras funerarias y forman parte de dos colecciones, la XXV Expedición del Museo Etnográfico (ME) de la Facultad de Filosofía y Letras de la Universidad de Buenos Aires (UBA) y la Colección Márquez Miranda (CMM) del Museo de La Plata (MLP) de la Universidad Nacional de La Plata.

\section{Valle de Iruya}

Casanova (1930) excavó en el adoratorio incaico de Cerro Morado a 5.200 msnm. Allí no registró entierros humanos, pero halló fragmentos de piezas de oro, plata, cuentas, entre ellas una de Spondylus sp. (mullu), y cerámica inca, que consideró habrían sido ofrendas. En dos estructuras detectó la presencia de una gruesa capa de "tierra vegetal alóctona" (Casanova, 1930, p.40). Esta práctica, que también se ha detectado en otros cerros con construcciones incaicas, llevó a Juan Schobinger a plantear la posibilidad de que en este sitio se hubiera llevado a cabo "uno de esos casos de sacrificio sustitutivo o simbólico", que habría sido saqueado previamente a la excavación de Casanova (Schobinger, 1966, p.13).

En Titiconte, asentamiento ubicado en el valle de Iruya a 2.760 msnm, Debenedetti y Casanova (1933-35) excavaron en unos 50 puntos, según indica el plano que se adjunta al trabajo. En el interior de las estructuras residenciales detectaron dos formas de entierros

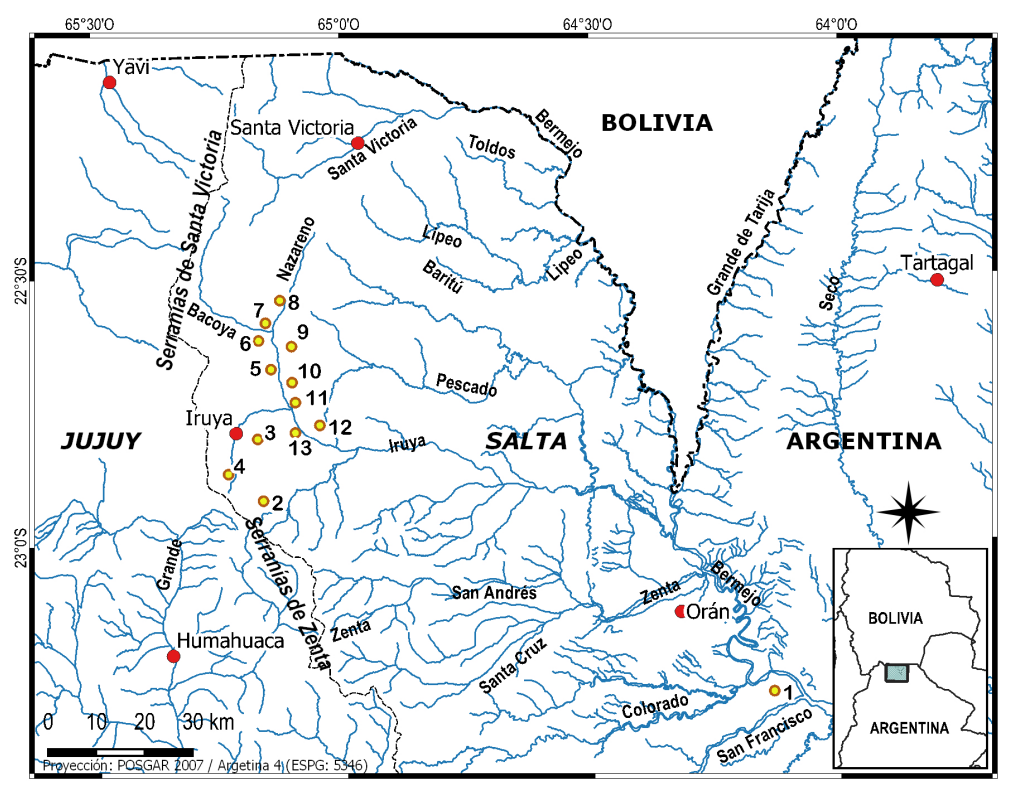

Figura 1: Sector de los valles orientales de Salta con ubicación de los sitios arqueológicos: 1-Manuel Elordi 1/ 2-Cerro Morado /3-Titiconte / 4-"Pucara" pie de la Cuesta de Colanzulí/ 5-Alto El Chañar/ 6-Pueblo Viejo de Rodeo Colorado (PVRC)/ 7-Molino Viejo/ 8-Cuesta Azul/ 9-Huaira Huasi/ 10-Zapallar/ 11-Higueras/ 12-Chaupi Loma/ 13-Arcayo.

Figure 1: Archaeological sites in the sector of eastern valleys of Salta: 1-Manuel Elordi 1/ 2-Cerro Morado /3-Titiconte / 4-"Pucara" pie de la Cuesta de Colanzulí/5-Alto El Chañar/ 6-Pueblo Viejo de Rodeo Colorado (PVRC)/ 7-Molino Viejo/ 8-Cuesta Azull 9-Huaira Huasil 10-Zapallar/ 11-Higueras/ 12-Chaupi Lomal 13-Arcayo. 
humanos: de adultos, en sepulcros construidos con paredes de piedra, en unos casos de formas rectangulares, aprovechando los ángulos de las habitaciones y, en otros, los sepulcros tenían forma redonda y se ubicaban en el centro de las viviendas. Se hallaban entre 1 y 1,50 m de profundidad. La otra forma de entierro corresponde a los párvulos colocados en el interior de urnas cerámicas (Debenedetti y Casanova, 1933-35). En las excavaciones en Titiconte registraron también un sepulcro de forma cuadrada ubicado en uno de los ángulos de una vivienda (Hallazgo I). A un metro de profundidad hallaron una vasija con los restos de un párvulo, carbones y un pequeño vaso cerámico. En el exterior del sepulcro, junto a sus paredes, había cuatro piezas de metal, dos manos de mortero y tres palas de piedra. Al igual que algunas otras viviendas, esta tenía un túnel que comunicaba con una estructura subterránea. Allí, entre los 0,80 y 1,20 m de profundidad descubrieron dos vasijas grandes con restos de párvulos, un hacha, un martillo y varias palas de piedra.

Estos investigadores advierten la mala conservación de los restos humanos y de la cerámica, por lo cual no pudieron extraer los huesos y solamente exhumaron dos vasijas usadas como urnas de párvulos. Registraron cinco entierros de párvulos en urnas toscas y sin decoración. Dos de ellos se hallaban al lado de esqueletos de adultos (Debenedetti y Casanova, 1933-35). Según los autores, las vasijas cerámicas parecen haber sido usadas primeramente como artefactos de cocina y transformadas luego en urnas funerarias de párvulos. En algún caso hallaron la urna rota en el cuello y en su parte superior, lo cual consideran que se hizo, posiblemente, para depositar el cadáver del niño, colocando luego una piedra laja redonda tapando la urna (Debenedetti y Casanova, 1933-35).

Los materiales que acompañaban los entierros corresponden a cuentas, piezas de metal de plata y de bronce de formas rectangulares y circulares, un cincel y una pieza antropomorfa de bronce. En un recinto, junto a un esqueleto humano hallaron tres piedras de boleadoras como único ajuar funerario (Debenedetti y Casanova, 1933-35).

Márquez Miranda (1939) excavó también en Titiconte y encontró un tercer tipo de entierro en "cámara sepulcral", ubicada en el subsuelo de un recinto habitacional de 5,65 m x 4,60 m, en uno de los ángulos interiores. En su excavación en el recinto halló un "hermoso topo de hueso" y una pala plana grande. El entierro, ubicado a 0,66 m de profundidad, era de forma cuadrada, con una gran laja que le servía de tapa, medía en su interior 0,70 $\mathrm{m} \times$ 0,72 $\mathrm{m}$ y $0,70 \mathrm{~m}$ de profundidad. Su construcción era simple, pero realizada con esmero y sus lados estaban formados por cuatro lajas grandes. La reducción del tamaño de la boca de la estructura, en comparación con la amplitud del recinto estaba lograda por medio de una serie de lajas menores, estrechas y largas, colocadas sobre las cuatro paredes a manera de tirantes líticos que sostenían la gran tapa, la cual excedía ampliamente el tamaño de la boca, para asegurar su cierre (Márquez Miranda, 1937, p. 158). En el fondo de la tumba se hallaban dos esqueletos en muy mal estado de conservación, lo que impidió su extracción. El ajuar funerario consistía en seis cuentas ("guayquitas") de hueso y piedras de color, redondas y de tamaño desigual, trocitos de madera, un fragmento de textil, posiblemente el reborde de una prenda de color verde y una pequeña cesta ovalada de mimbre tejido. Esta pieza, por su ubicación en el entierro debió colocarse en último término, sobre todo lo demás (Márquez Miranda, 1937). Al igual que Debenedetti y Casanova (1933-35), Márquez Miranda realizó sus investigaciones durante la estación de lluvias y destaca el problema de la humedad en el sedimento y en los restos arqueológicos.

En sus excavaciones en el "Pucará" del Pie de la cuesta de Colanzulí, ubicado al sur de Iruya, Márquez Miranda (1934) registró también un entierro con las mismas condiciones de pésima conservación del material óseo humano. Al excavar un recinto habitacional en el sitio encontró al lado del esqueleto y por encima de él restos de carbón de un fogón. A un costado y a 0,60 m de profundidad halló trozos de un punzón y de un "cuchillo", y a 0,95 $\mathrm{m}$ de profundidad, tres palas planas de piedra de formas diferentes, todas ellas a muy escasa distancia unas de otras (Márquez Miranda, 1934).

Posteriormente, Rodolfo Raffino y colaboradores (1986) relevaron Titiconte, sitio que consideraron un centro administrativo incaico. Registraron también las estructuras de Arcayo y Zapallar (Figura 1), que ya habían sido excavadas por Márquez Miranda (1939), confirmando la presencia en estos sitios de almacenes (collcas) incas (Raffino, 1993).

\section{Valle de Bacoya}

En sus excavaciones en Molino Viejo, sitio ubicado sobre el valle del río Bacoya a 2760 msnm, Márquez Miranda registra que el sedimento era más seco que en el cercano sitio de Pueblo Viejo de Rodeo Colorado (ver más adelante), sin embargo, los restos humanos tenían peor conservación. En Molino Viejo no se había usado barro amasado para asegurar las tapas de lajas en las sepulturas y las paredes se levantaban sin cemento ni unión alguna, lo cual planteaba diferencias con otros sitios (Márquez Miranda, 1939).

\section{Valle de Nazareno}

En Cuesta Azul, sobre el valle de Nazareno, Márquez Miranda excava una amplia sepultura pircada, de forma oval, de techo abovedado a 0,60 $\mathrm{m}$ de profundidad, formada por varias lajas, la más grande de 0,70 m de largo y 0,36 m de ancho. La cámara sepulcral tenía diámetros máximos de 1,10 m por 0,85 m. La tumba parecía intacta. Bajo la superficie aparecía una gruesa capa de tierra negra, luego otra de barro amarillo amasado y más abajo de aquella, otra de barro colorado amasado. Recién después de este doble sello, se llegaba a las lajas que 
componían la tapa de la sepultura y que, a su vez, estaban sustentadas por un verdadero armazón de "tirantes" de piedra (Márquez Miranda, 1939, p.154). La tumba aparecía vacía hasta una altura de 0,65 metros desde el techo y luego presentaba una capa de tierra fina de $0,30 \mathrm{~m}$ de espesor, que llegaba hasta el fondo, en la que se encontraban los restos de tres esqueletos humanos, así como un rico instrumental de cobre, compuesto de punzones y cuchillos, que se agrupaban en torno de las respectivas calotas craneanas, así como también algunos otros objetos del ajuar funerario. El investigador destaca que muchas piezas de metal conservaban aún sus cabos de madera'. En este entierro, al igual que en otros, halló una gran pala plana, formando parte de la pared y a una profundidad de 0,05 $\mathrm{m}$ a partir del techo de la estructura. Los tres esqueletos se hallaban muy deteriorados, por lo cual Márquez Miranda no los extrajo.

Señala como una costumbre local bastante frecuente la de superponer los cementerios actuales con los lugares en donde los antiguos pobladores de la región habitaron y enterraron a sus muertos. Esto ocurre en Cuesta Azul, en Higueras y en otro sitio, cuyo nombre no menciona, en el valle de Bacoya ubicado a $15 \mathrm{~km}$ al oeste de Molino Viejo (Márquez Miranda, 1939).

En 1934 Márquez Miranda excavó en Alto el Chañar en donde halló siete esqueletos sin ajuar, sin ornamentación y en distintas posiciones (Márquez Miranda, 1939). Mientras que en Chaupi Loma, encontró una cámara subterránea vacía, similar en su construcción a la cámara sepulcral que halló en Huaira Huasi.

En Zapallar a 2020 msnm Márquez Miranda registró un gran número de entierros, que en varios casos corresponden al tipo de forma cuadrada, formado por cuatro lajas. Debajo de ellas se encontraban otras lajas que correspondían a la tapa del recinto funerario y luego lajas grandes colocadas verticalmente, o hiladas de piedras dispuestas horizontalmente, formando la pared del recinto o cámara de la sepultura, que siempre tenía forma redondeada (Márquez Miranda, 1939, p.177). En la construcción a veces se usaron pequeñas piedras para rellenar los espacios libres entre las grandes lajas. En algunas ocasiones estas sepulturas podían ser múltiples. Junto a este tipo de entierros Márquez Miranda halló dentro de un gran hoyo en la tierra y en torno a una ollita, ocho esqueletos en mal estado de conservación por la humedad del terreno, de los cuales recogió los cuatro cráneos menos destruidos ${ }^{2}$. En este sitio también registró entierros en urnas funerarias de diversos tipos, algunas, tenían formas globulares, mientras que otras eran más parecidas a los vasos tubulares, pero de menor tamaño. En todos los casos carecían de decoración, con asas principalmente horizontales, algunas de bases amplias y

1 En la Colección Márquez Miranda (MLP) no hallamos estas piezas de metal con cabos de madera.

2 Estos cuatro cráneos no se hallaron en la Colección Márquez Miranda (MLP), ni están registrados en las fichas del inventario. otras reducidas (Márquez Miranda, 1939, p.181).

Al oeste del valle de Nazareno, Márquez Miranda excavó en otro asentamiento residencial, Pueblo Viejo de Rodeo Colorado (PVRC), que podríamos considerar de grandes dimensiones para la región. Este sitio fue construido en la ladera media de un cerro, a 3200/ 3300 msnm, en ambiente de Pastizales de Neblina, frente a un abra que en tiempos de Márquez Miranda, (1939) se denominaba "Abra de las Sepulturas" y, actualmente, Abra del Sauce ${ }^{3}$. PVRC se halla rodeado por un amplio sector con andenería agrícola de notable calidad que se extiende hacia el suroeste, hasta el pueblo actual de Rodeo Colorado, en donde también localizamos un sitio arqueológico (Ventura, 1999). PVRC fue excavado por Márquez Miranda en 1933 y en 1938, contaba con unas 100 estructuras o recintos habitacionales simples, de formas circulares-elípticas de unos 4 a 7 m de diámetro, con paredes de piedra doble. Estas estructuras se hallaban distribuidas en forma escalonada en la ladera, con muros de contención y con áreas de circulación bien definidas. En la parte baja del sitio había una surgente de agua (Márquez Miranda, 1939).

El investigador refiere a las modificaciones que habían realizado las actuales poblaciones locales en el sitio. Entre ellas, la construcción de muros ("pircados") separando terrenos, paredes de viviendas actuales y corrales para ganado, utilizando las piedras de las estructuras antiguas. La surgente de agua, en la que los primeros ocupantes del sitio habían levantado un muro de contención, fue modificada y los actuales pobladores construyeron una boca de salida para el agua y un pequeño estanque de embalse (Márquez Miranda, 1939).

A fin de entender las modificaciones que las excavaciones de Márquez Miranda causaron en el sitio, referiremos que en 1933 excavó seis recintos en la parte inferior del sitio. En 1938 continuó excavando las estructuras desde abajo hacia arriba

"subiendo por la ladera a medida que se vayan desarrollando los trabajos. Dada la configuración del terreno esto es lo más aconsejable, para que la tierra que se desmonte pueda ser arrojada, cada vez hacia el nivel inferior, ya explorado"(Márquez Miranda, 1939, p.213).

En PVRC excavó un total de 18 recintos, exhumando abundantes materiales, principalmente en los enterratorios. Estos se ubicaban siempre en el interior de los recintos habitacionales, debajo de los pisos, cerca de las paredes, aunque en un caso se hallaron en el centro del recinto. En este sitio detectó un tipo de vasijas cerámicas de grandes proporciones (ca. un 1 metro de alto), a los que denominó "vasos tubulares" por su morfología. Estas piezas carecen de decoración, al igual que otras grandes

3 Actualmente, en este lugar se ha instalado una pequeña localidad, donde también se han registrado materiales arqueológicos. 
vasijas ápodas. Consideró que algunas de estas vasijas sirvieron para almacenar granos o líquidos y otras tuvieron fines funerarios. Estos vasos tubulares a veces aparecían en grupos de dos o tres en el subsuelo de un mismo recinto habitacional y, en algún caso, bajo los cimientos de la pared de la vivienda (Márquez Miranda, 1939).

Las diversas formas de enterratorios halladas en PVRC corresponden a:

a) cámaras redondas $u$ ovaladas y, en algunos casos, poligonales, con paredes pircadas y techo en falsa bóveda,

b) cámaras rectangulares realizadas con lajas, con una gran laja como tapa,

c) urnas cerámicas, colocadas directamente en tierra, con una laja como tapa.

d) entierros directos en tierra.

Márquez Miranda (1939, p.138) destaca las diferencias entre estos tipos de sepulturas "empleados simultáneamente en el mismo yacimiento, y aún, en el subsuelo de una misma habitación". Para la construcción de las cámaras sepulcrales se utilizaron piedras rodadas y lajas y, a veces, una combinación de ambas. Una característica de éstos entierros era que, tanto en los recintos funerarios como en el caso de las urnas se hallaban cubiertos de una gruesa capa de barro amasado de color rojo o amarillo, que a veces llegaba a medir 20 cm de espesor y que servía de cierre al entierro (Márquez Miranda, 1937).

El investigador describe la forma en que se presentaban los hallazgos de los entierros:

“Una vez removida la capa superficial de tierra suele aparecer un pequeño piso, formado por una gran losa cuadrada o redondeada, o por tres o cuatro lajas cuadrangulares (fig. 13a). En este último caso, estas suelen reposar sobre otras más angostas y espaciadas colocadas a modo de tirantes o soportes sobre el borde superior de la pirca subterránea que limita y sirve de pared a este pequeño recinto funerario. La boca de la sepultura -que al quitarse la tapa queda al descubierto- suele ser de una amplitud y diámetro inferior al del propio recinto sepulcral. En éste suelen depositar los restos de más de un individuo, sobre unos cuantos centímetros de tierra muy fina, acompañándolos del ajuar funerario (fig. 13 b)" (Márquez Miranda, 1941, p.223).

En relación a las cámaras funerarias con paredes de piedra el investigador menciona el hallazgo, inmediatamente después de las lajas que sirven de tapas, y como parte de la hilada superior de piedras que constituyen el sector más alto de la pared, de una o varias palas planas y, a veces, con menos frecuencia, manos de mortero, piedras de moler u otros objetos. Destaca la alta proporción de casos en que las palas planas se registran en los contextos funerarios por lo cual las considera "instrumental asociado al culto de los muertos"(Márquez Miranda, 1939, p.
218). El reiterado hallazgo de palas planas colocadas en las paredes de las estructuras funerarias lleva a Márquez Miranda a preguntarse si podrían ser herramientas consideradas sagradas luego de haber sido empleadas en tareas relacionadas con el culto a los muertos. Esto podría ser la razón por la cual se las dejaba allí formando parte de la tumba, o a disposición del muerto como instrumento requerido para su salida de la tumba hacia su otra vida, o como instrumento que se proveía al fallecido para sus necesidades en la otra vida. En un caso una de estas palas planas de tipo común cubría, a modo de tapa, una vasija utilizada como urna funeraria. Márquez Miranda (1939) considera que el tipo especial de algunas de estas palas planas, finamente trabajadas, de gran tamaño y delgado espesor, con grandes aletas altamente decorativas es coherente con su uso ceremonial.

Destaca que la humedad del subsuelo llevó a la destrucción, casi absoluta, del material antropológico y los restos humanos se hallan "en estado pulvelurento, ya deshechos o deshaciéndose al menor contacto" y los pocos hallazgos de cráneos humanos en "excepcionales condiciones de conservación", corresponden a casos de deformación craneana de tipo erecto (Márquez Miranda, 1939, p.139).

En su publicación de 1939 Márquez Miranda refiere que se hallaba escribiendo un artículo sobre los hallazgos arqueológicos de estos valles, trabajo que nunca publicó y cuyo manuscrito no logramos ubicar a pesar de nuestras averiguaciones. Seguramente, el investigador levantó la planta de PVRC y registró mayores detalles sobre los contextos de hallazgos, pues en las fichas del Inventario del MLP a veces se menciona el número del recinto del cual proviene la pieza. Sin embargo, sus libretas de campo con los dibujos de las plantas de los sitios no se encuentran en ese Museo donde están depositados sus materiales. Sin duda, se ha perdido una enorme cantidad de información sobre las excavaciones que este investigador llevó a cabo en esos valles orientales. Algunas fotos de sus campañas se encuentran en los archivos del Museo Etnográfico de Buenos Aires. En sus publicaciones Márquez Miranda tampoco realiza propuestas cronológicas sobre los materiales exhumados.

\section{Nuestros trabajos}

Las investigaciones arqueológicas que llevamos a cabo en estos valles orientales incluyeron el estudio y análisis de los materiales provenientes de las excavaciones de Casanova y Debenedetti, principalmente de la Colección Márquez Miranda del MLP (Becerra, et al., 2020; Granda, 2011; Ventura, 2011, 2019). Integramos esos datos con los obtenidos en nuestros propios trabajos de campo, con el estudio de documentación y cartografía histórica (Oliveto y Ventura, 2017; Ventura y Oliveto, 2014) y de la geología regional (Ventura y Scambato, 2013). Sobre esta base hemos propuesto que durante la ocupación 


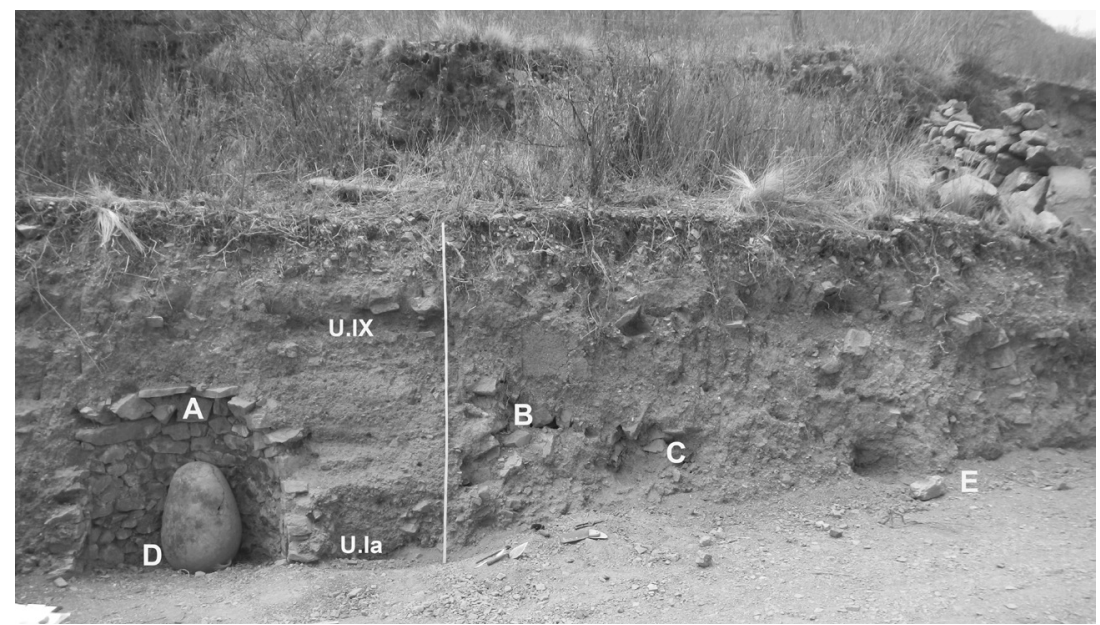

Figura 2: Sector del camino en PVRC. Se indican: A- estructura, B-estructura muy destruida, C- cráneo fragmentado en el perfil, D- vasija ovoide, E-ubicación en el camino de la urna con cráneo y ajuar en su interior, U.la y U.IX -niveles datados en el perfil.

Figure 2: Sector of the road at PVRC. The numbers indicate: $A$ - structure, $B$ - destroyed structure, $C$-fragmented skull registered in the profile, D- ovoid vessel, E- location of the urn with skull and goods directly on the road, U.Ia and U.IX-dated layers in the profile.

inca en estos valles y serranías los objetivos fueron principalmente la explotación minero-metalúrgica, para lo cual se re-localizaron distintas poblaciones, dejando una fuerte impronta en los valles con la construcción de una extensa andenería y recintos de almacenaje. Un par de centros administrativos fueron levantados sobre los valles de Iruya y Nazareno, implementando la dominación simbólica sobre este paisaje con un adoratorio de altura en Cerro Morado (Ventura, 2016, 2017).

En los trabajos de campo llevamos a cabo prospecciones, excavaciones y rescates. En la primera campaña en Rodeo Colorado en 1982 relevamos el asentamiento residencial de PVRC. En esa oportunidad observamos que un deslizamiento de rocas y barro había cubierto gran parte del sitio que había excavado Márquez Miranda en la década de 1930, quedando al descubierto solamente unas 30 estructuras circulares, que se distribuían en 10 terrazas artificiales, separadas por muros de contención, con sectores de circulación bien definidos entre las estructuras y aún se conservaba activa la surgente de agua. En el interior de algunas estructuras se distinguía, junto al muro, la cámara funeraria abierta. Suponemos que habían sido excavadas durante los trabajos de Márquez Miranda, ya que el sitio no parecía huaqueado ni impactado por nuevas construcciones, más allá de las registradas por ese investigador (Ventura, 1999).

En 2011 regresamos al sitio y observamos que las comunidades locales (de Rodeo Colorado y Abra del Sauce) habían construido en 2001 un camino vehicular que recorre, zigzagueando, la ladera del cerro, transitando sobre el sitio arqueológico. Los pobladores habían edificado en el sitio un lavadero de animales y levantado muros ("pircados") con las piedras de algunas de las estructuras arqueológicas. También, en la surgente de agua se había conectado la manguera que distribuye el agua a los asentamientos actuales. Todas estas obras habían modificado de manera notable el sitio y para entonces solamente se registraban unas 25 estructuras muy destruidas. En uno de los perfiles dejados por la construcción del camino comenzaba a aparecer una estructura circular. El agujero causado en sus paredes dejaba ver su interior, que se hallaba vacío. Las paredes, construidas con piedras seleccionadas, principalmente rectangulares y de tamaños similares, finalizaba en su parte superior en forma de falsa bóveda y una laja le servía de tapa.

En 2013 el camino vehicular fue ensanchado con maquinarias de Vialidad Provincial, aumentando el destrozo del sitio, dejando muy pocos recintos habitacionales sin impactar. Observamos numerosos fragmentos de huesos humanos dispersos en la superficie del camino vehicular y, a su costado, los restos de las estructuras funerarias destruidas que habían estado ubicadas en el interior de los recintos habitacionales. En

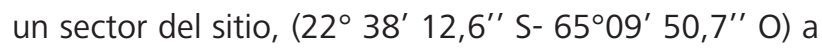
3313 msnm, notamos la aparición de vasijas cerámicas aflorando en la superficie del camino y de restos óseos humanos, fragmentos de cerámica y carbones en los bordes del camino. La construcción del camino dejó, en ciertos sectores, perfiles de más de 2 metros de alto. Junto con la Dra. María Ester Albeck fotografiamos y realizamos la limpieza de uno de estos perfiles expuestos y recolectamos carbones, algunos de los cuales han sido datados (ver más adelante) (Figura 2). Albeck dibujó los distintos niveles de ocupación, que claramente se manifestaban en el perfil. En esa campaña excavamos también una cuadrícula en el interior de uno de los recintos circulares ( $R$ 7), donde no registramos restos orgánicos que pudieran ser fechados.

\section{Primer rescate (2013)}

La construcción del camino dejó al descubierto una de las estructuras circulares, denominadas "cámaras funerarias" por Márquez Miranda, que en el año 2011 recién comenzaba a aflorar en el perfil y la ampliación del camino la cortó por la mitad (Figura 2-A). Sus medidas son 1,05 $\mathrm{m}$ de alto y 1,14 m de diámetro máximo y, a 0,80 $\mathrm{m}$ del piso de la estructura, la parte superior de la pared comienza a inclinarse hacia adentro conformando la falsa bóveda. A un metro de esta estructura identificamos 
otra de similares características, muy destruida (Figura 2-B). Siguiendo el perfil dejado por el camino, a unos $0,60 \mathrm{~m}$ hacia el Este, afloraba un cráneo humano muy fragmentado, que retiramos (Figura 2-C).

Durante la construcción del camino los obreros hallaron una vasija cerámica de forma ovoidal, base redondeada, levemente acuminada, con dos asas laterales cercanas al borde. El cuello y los bordes de la pieza estaban fragmentados, con fracturas recientes. Sus medidas son: 0,66 $\mathrm{m}$ de alto, 0,40 $\mathrm{m}$ de diámetro, 0,20 $\mathrm{m}$ en la base y ca. 0,22 m en la boca fragmentada. Las paredes exteriores tienen superficies alisadas, de color gris oscuro y no presentan decoración. Tiene dos asas horizontales, en cinta, doble remachadas ubicadas cerca del cuello (Figura 2-D). En el interior de la vasija había una piedra alargada que no se retiró, pero tomamos una muestra del sedimento quemado hallado en el interior de la vasija. Esta pieza había sido colocada por los obreros en el interior de la estructura circular que quedó al descubierto en esa oportunidad (Figura 2-A), pero la vasija no fue hallada en ese lugar del sitio 4 .

En la superficie del camino, a 5,60 $\mathrm{m}$ de la estructura descripta, se destacaba la forma circular de una vasija cerámica (Figura 2-E). Considerando la pronta destrucción de esta pieza debido al paso de vehículos, decidimos realizar su extracción. En su interior hallamos pequeños fragmentos cerámicos y una punta de proyectil de riolita negra ${ }^{5}$, de limbo triangular y base escotada (Figura 3-C). También, dentro de la vasija, a 0,28 $\mathrm{m}$ de profundidad hallamos un cráneo humano con deformación (Figura 3A y B). Debajo del cráneo registramos dos cuentas circulares planas de color verde claro, las cuales fueron analizadas y determinadas como turquesa (Becerra, et al., 2020) (Figura 3-C). La vasija cerámica es ovoide, de 0,50 $\mathrm{m}$ de alto (está fragmentada en el sector superior) su diámetro máximo es de 0,43 $\mathrm{m}$ y el espesor de las paredes $0,7 \mathrm{~cm}$. La base es plana, de $7 \mathrm{~cm}$ de diámetro y la superficie de la vasija, tanto exterior como interior está alisada y no tiene decoración.

En oportunidad de este primer rescate, el Consejo Kolla Unido de Rodeo Colorado y Abra del Sauce no permitió la salida fuera de la comunidad de los restos óseos humanos para su estudio y decidió volver a enterrarlos en un lugar determinado dentro del sitio arqueológico. Allí sepultaron gran cantidad de huesos que se hallaban dispersos en el camino, resultado de la ampliación de éste por las máquinas de Vialidad. Junto a estos huesos fue inhumado el cráneo recuperado dentro de la urna y los extraídos del perfil dejado por el camino. Esto se realizó con el ritual correspondiente (ofrendas de hojas de coca,

\footnotetext{
4 Esta vasija luego de ser medida y fotografiada fue trasladada por miembros de la comunidad de Abra del Sauce hasta la Sala de Salud en donde quedó depositada, al igual que otros materiales arqueológicos registrados en esa localidad.

5 Analizada por EDX por Mariana Rosenbusch (Centro Atómico Constituyentes-CNA, en 2017).
}

alcohol y agua bendita) por parte de dos miembros de la comunidad de Abra del Sauce y por nuestro equipo que fue invitado a participar del mismo.

Sobre la base del análisis de las fotografías del cráneo registrado dentro de la urna, consideramos que se trata de un individuo masculino adulto joven de acuerdo con la secuencia de obliteración de las suturas craneales, el bajo desgaste observable en la dentición y el hecho de que el tercer molar permanente de la arcada superior derecha se encuentra en erupción (se observa la corona completa sobre el alvéolo). El cráneo presenta deformación tabular oblicua y se observa anormalidad en la forma del hueso nasal izquierdo que podría ser compatible con una fractura premortem.

\section{Segundo rescate (2014)}

En la campaña del año 2014, junto con la Dra. María Florencia Becerra realizamos un nuevo rescate en PVRC, debido a la aparición de huesos humanos cercanos a una concentración artificial de cenizas. Allí, la acción erosiva del agua que escurre desde el sector superior ha ido cavando, produciendo un perfil del que afloraban los huesos humanos. El lugar de este hallazgo se halla en el exterior de las estructuras. Los huesos fueron extraídos luego de la consulta y previo permiso de la dirigencia del Centro Kolla de Abra del Sauce y con la presencia de un veedor nombrado por ellos.

Se marcaron siete apariciones de restos humanos en superficie en distintas posiciones dentro de un área de aproximadamente seis metros, algunos se hallaban directamente en la superficie del terreno. Luego de la extracción los restos humanos fueron presentados a la comunidad de Abra del Sauce. Ante nuestra solicitud de estudiarlos, con la promesa de su posterior retorno, los dirigentes del Centro Unido de Rodeo Colorado y Abra del Sauce nos dieron el permiso.

El análisis de los restos óseos humanos se realizó en el Instituto de Arqueología de la Facultad de Filosofía y Letras (UBA). El primer paso consistió en el lavado de los restos óseos con agua corriente y cepillo suave. Este paso fue necesario debido a la presencia de abundante sedimento adherido en la superficie de los restos lo que impedía la correcta observación de puntos de medición o rasgos patológicos diagnósticos.

Una vez que los restos estuvieron secos se procedió a su estudio, dado que los restos fueron recibidos como un conjunto óseo sin individualizar, se procedió al inventariado del material a fin de establecer el número mínimo de individuos y evaluar si eran identificables el sexo y edad de los individuos siguiendo a Buikstra y Ubelaker (1994). También se tomaron mediciones ${ }^{6}$ en huesos largos incompletos para proceder a la reconstrucción

6 Las medidas fueron tomadas con un calibre recto digital Mitutoyo Serie 500 con una precisión de $\pm 0,02 \mathrm{~mm}$. 
Figura 3: A- Interior de la urna, B- detalle del cráneo con deformación, C- punta de proyectil y cuentas turquesa. Rescate 2013.

Figure 3: A-Interior of the urn, $B$ - detail of the skull with human modifications, C-projectile point and turquoise beads obtained during rescue in 2013.
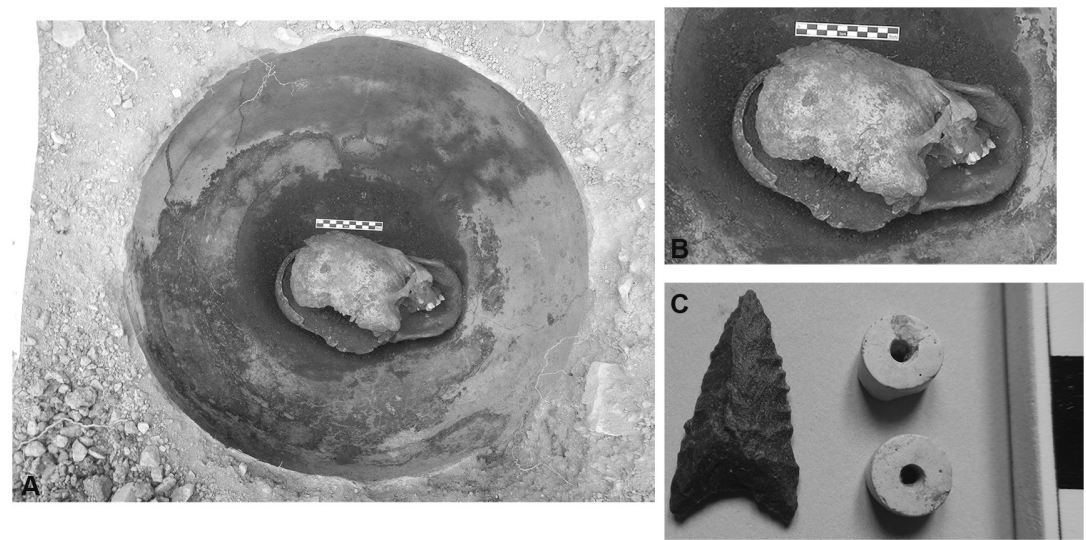

de la estatura según la metodología de Steele y McKern (1969), basada en el porcentaje de cada segmento en la composición total del hueso. Si bien no poseemos restos óseos de otros conjuntos de la zona con los que comparar la información de la estatura como marcador general de estrés, se considera importante informar este rasgo para futuras comparaciones poblacionales a nivel regional o extra- regional, sobre todo considerando que los restos fueron devueltos a la comunidad de origen.

Sobre la base del inventario realizado (Tabla1) pudimos estimar que el conjunto óseo se encontraba en buenas condiciones de conservación y está compuesto por los restos de al menos dos individuos adultos, cuya unidad esqueletal se ha perdido y que no cuenta con representación de todas las secciones anatómicas del esqueleto (i.e. ausencia de restos craneales, huesos de la mano y la mayoría de los del pie, así como la cintura pélvica). Desconocemos si esta representación diferencial está vinculada con el tipo de entierro realizado originalmente o con movimientos posteriores de los restos, incluso en momentos actuales.

La estatura se estimó a partir de la reconstrucción de la longitud total de los huesos largos presentes. Teniendo en cuenta que no ha sido posible determinar el sexo de los individuos debido a la ausencia de las estructuras más confiables para la realización de esta tarea, que son la pelvis y el cráneo, la estatura se estimó para cada hueso largo considerando las fórmulas para femeninos y masculinos presentadas por Pommeroy y Stock (2012) (Tabla 2). De esta manera, los resultados de la Tabla 2 representan a los elementos óseos y no a los individuos, dado que no fue posible re-asociar los restos para alcanzar la unidad individual. Finalmente, no se hallaron señales esqueletales de estrés en los restos óseos presentes.

Considerando además los hallazgos previos, es interesante el registro en la Colección Márquez Miranda (MLP) de tres cráneos con deformación. Márquez Miranda (1939, p.139) refiere que en los pocos casos de cráneos hallados en sus excavaciones en buenas condiciones, estos presentaban "deformación craneana tipo erecto". Sin embargo, los únicos restos humanos de los valles orientales registrados en esa Colección (MLP) corresponden a tres cráneos hallados dentro de una gran vasija cerámica, asignados en el Inventario como provenientes de "Departamentos de Iruya y Santa Victoria N ${ }^{\circ}$ 7092/24.306"7. El análisis de los mismos fue llevado a cabo por la Dra. Susana Salceda (MLP), quien determinó que se trataba de los cráneos de dos niños y de una mujer, los tres con deformación tabular oblicua (Salceda, com. per. 2011).

\section{Propuesta Cronológica}

Márquez Miranda no estableció una posible cronología para los sitios excavados. Sin embargo, menciona las diferentes profundidades en las que se hallaban los grandes "vasos tubulares", colocados debajo de los cimientos de los muros en el interior de las viviendas de PVRC, dando a entender la existencia de al menos dos momentos de ocupación del sitio (Márquez Miranda, 1939, fig.28, p.131). Refiere que, en ciertos casos, estos vasos cerámicos "se encuentran a un nivel inferior aún que el de las cámaras funerarias" (Márquez Miranda, 1939, p.218).

Posteriormente Wendell Bennett (1948a), sobre la base de los materiales recuperados en las expediciones de Casanova y Debenedetti (1933-35) y de Márquez Miranda (1937, 1939), definió el "Iruya Complex" considerándolo tardío (900-1500 DC), incluyendo claramente la presencia incaica en sitios como Titiconte, Colanzulí, Rodeo Colorado y otros. Para dicha propuesta Bennett utiliza indicadores arquitectónicos, cerámicos y líticos, que relaciona explícitamente con Tolomosa, en los valles orientales de Tarija, en el sur de Bolivia, considerando que el material incaico es "casi idéntico" al de los sitios del Iruya Complex (Bennett, 1948b:146).

Más tarde, Guillermo Madrazo y Marta Ottonello (1966) relacionaron los grandes vasos tubulares hallados en Rodeo Colorado con otros similares encontrados en Estancia Grande, en la Quebrada de Humahuaca y propusieron

7 No hay registro en los escritos de Márquez Miranda sobre el hallazgo de esos cráneos, por lo tanto, manejamos este dato con cierta reserva, ya que no sabemos si se encontraron originalmente dentro de esa vasija y si sólo se recuperaron los cráneos. 


\begin{tabular}{|l|l|l|l|}
\hline \multicolumn{1}{|c|}{ Elemento } & Lateralidad & NMI & \\
\hline Húmero & Derecho & 1 & Pérdida de sustancia ósea en extremidad distal. Presenta abertura septal. \\
\hline Radio & Izquierdo & 2 & Pérdida de sustancia ósea en ambas epífisis. \\
\hline Fémur & Derecho & 1 & \\
\hline Fémur & Izquierdo & 1 & \\
\hline Cúbito & Derecho & 1 & Solo diáfisis \\
\hline Cúbito & Indet. & 1 & Dos fragmentos de olecranon quemados que remontan entre sí. \\
\hline Peroné & Indet. & 1 & Fragmento \\
\hline Vértebra & - & 1 & Fragmento \\
\hline 2do Metatarsiano & Derecho & 1 & Fragmento \\
\hline Escápula & Izquierda & 1 & \\
\hline Costillas & Derecha & 1 & Fragmentos de 4 costillas \\
\hline Costillas & Izquierda & 1 & Fragmentos de 3 costillas \\
\hline Tibia & Izquierda & 1 & Ambas epífisis ausentes postmortem \\
\hline Sin identificar & Indet. & & Fragmento de resto óseo sin identificar \\
\hline
\end{tabular}

Tabla 1: Inventario de los restos óseos humanos. Rescate 2014

Table 1: Inventory of human skeletal remains. Rescue activities in 2014

separar este Complejo en Iruya Inicial e Iruya Tardío. Este último tendría un patrón arquitectónico distinto del anterior, con conglomerados y unidades compuestas, aunque también habría sitios con habitaciones de plantas circulares y rectangulares, que incluirían las ocupaciones incaicas y que coincidiría con la ubicación cronológica que Bennett (1948) atribuía al Iruya Complex. José Pérez (1968) menciona el Iruya I (300 AC al 500 DC), el Iruya II (900DC al 1000 DC) y el Iruya Tardío (1000 DC-1480 DC). Sin embargo, estos interesantes planteos cronológicos no fueron contrastados con el registro arqueológico por estos investigadores (Ventura, 1999).

Producto del rescate del año 2014 en PVRC realizamos un fechado radiocarbónico sobre un fémur humano que dio como resultado: 1510 \pm 80 AP (LP 3170) cal. AD 413-770 (2 sigmas). Este fechado se corresponde cronológicamente con la datación de una muestra de carbón proveniente del perfil dejado por la construcción del camino, en donde se pueden observar claramente los niveles de distintas ocupaciones del sitio (Figura 2). El nivel inferior (U.la) fue datado en $1595 \pm 40$ AP (LuS 11168) cal. AD 416-596 (2 sigmas). Otra muestra de carbón de un nivel superior (U. IX) registró un fechado de $845 \pm 35$ AP (LuS 11167) cal. AD 772-990 (2 sigmas). Aún queda por datar el nivel superior del perfil. Los fechados fueron calibrados con el programa OxCalv4.4.3 (Bronk Ramsey, 2009), utilizando la curva de calibración ShCal20 (Hogg et al., 2020) (Figura 4).

Algunas piezas recuperadas en los entierros por los investigadores de los años 1930 pueden ser indicadores de cierta cronología, como ya hemos propuesto en otras oportunidades (Ventura, 2016, 2019). La cerámica hallada en las inhumaciones es poco indicativa. Las urnas funerarias y los pequeños pucos que formaban parte del ajuar funerario no presentan decoración alguna o, en raras ocasiones, pintura negra. Uno de estos casos corresponde a dos baldes chichas (Tarragó, 1989), registrados en PVRC, que Florencia Avila (2011: 67) considera dentro del "Estilo
Calahoyo", asignándolo tentativamente al Período Medio o Formativo Tardío (500-900 DC). También, en PVRC y en Chaupi Loma se han hallado fragmentos y bordes de cerámica puneña (Yavi- Chicha), mientras que en PVRC, en Cuesta Azul, Huaira Huasi y Titiconte se registra cerámica y material lítico inca, entre ellos, una flauta tubular decorada (Ventura, 2016; Ventura y Becerra, 2018).

La presencia en Huaira Huasi de una placa de bronce de las Ilamadas placas rectangulares Calchaquíes tardías y pequeñas campanillas o cubiletes de oro, así como otros elementos de prestigio como pulseras, brazaletes tubulares (chipanas), brazales, manoplas de bronce y placas circulares de plata (tincurpa) en PVRC, refiere a poblaciones jerarquizadas y a interacciones a larga distancia (Ventura y Scambato, 2013; Ventura, 2019). El registro de numerosas cuentas de turquesa, sodalita, ópalo y malacológicas, alude a otros materiales valorados por estas poblaciones, pero a las cuales no podemos otorgarles una cronología tentativa. El hallazgo en Cuesta Azul de cuentas Nueva Cádiz, de entrada temprana en América, las ubica en momentos coloniales. Estas cuentas de vidrio han sido detectadas en otros sitios arqueológicos del NOA, donde se han registrado entierros atribuidos a personajes jerarquizados del siglo XVI, como en la Falda de Tilcara (Bordach, 2006) y en La Huerta (Raffino y Palma, 1993) en la Quebrada de Humahuaca, y en Cachi Adentro en el Valle Calchaquí (Tarrago, 1984). Estos sitios registran previamente importantes ocupaciones incas.

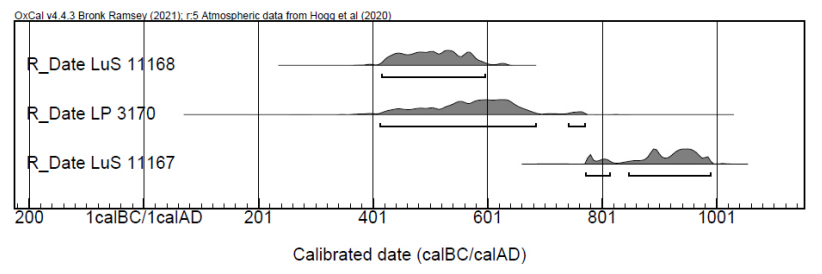

Figura 4: Gráfico con dataciones calibradas de PVRC

Figure 4: Calibrated radiocarbon dates from PVRC 


\begin{tabular}{|l|l|l|l|}
\hline \multicolumn{1}{|c|}{ Elemento } & \multicolumn{1}{|c|}{ Segmento utilizado } & \multicolumn{1}{|c|}{$\begin{array}{c}\text { Estimación de la } \\
\text { longitud (Steele \& } \\
\text { Bramblett 2000) }\end{array}$} & $\begin{array}{c}\text { Estimación de la } \\
\text { estatura (Pommeroy y } \\
\text { Stock 2011) }\end{array}$ \\
\hline Húmero & $\mathrm{H} 2$ & $\begin{array}{l}29,5 \mathrm{~mm}(\mathrm{~F}) \\
30,09 \mathrm{~mm}(\mathrm{M})\end{array}$ & $\begin{array}{l}154,30 \pm 2,975 \\
158,57 \pm 3.5522\end{array}$ \\
\hline Fémur derecho & $\mathrm{F} 2$ & $41,96 \mathrm{~mm}(\mathrm{~F})$ & $157,14 \pm 2,295$ \\
& & $41,95 \mathrm{~mm}(\mathrm{M})$ & $159,66 \pm 2,627$ \\
\hline Fémur izquierdo & F2 & $42,86 \mathrm{~mm}(\mathrm{~F})$ & $159,47 \pm 2,295$ \\
& & $43 \mathrm{~mm}(\mathrm{M})$ & $162,53 \pm 2,627$ \\
\hline
\end{tabular}

orientales. Estas piezas fueron esenciales en las comunidades agrícolas y mineras, utilizadas en los campos de cultivo, en tareas extractivas, en contextos domésticos y funerarios. Siguiendo a Haber y Gastaldi (2006, p.288) estos instrumentos fueron usados tanto

"... en las casas de los vivos como en las casas de los muertos-

Tabla 2: Estimación de la estatura de los huesos largos del conjunto óseo rescatado en 2014.

Table 2: Estimated stature of the long bones from the bone assemblage rescued in 2014.

Sin duda, PVRC es un sitio multicomponente, con ocupaciones que se extienden desde 400 D.C. hasta, al menos, el siglo XV. Desconocemos el inicio de las ocupaciones en otros sitios, pero evidencias de materiales hispano-indígenas en Cuesta Azul y en Molino Viejo extenderían el uso de esos asentamientos hasta, posiblemente, el siglo XVII.

\section{Consideraciones finales}

En los sitios excavados por los primeros investigadores en estos valles orientales los entierros fueron realizados debajo de los pisos de los recintos habitacionales. Esto señalaría la importancia de los muertos en la continuidad de la vida de los vivos, al ser enterrados en las viviendas en las que se desarrollan las tareas habituales cotidianas. La mayoría de los adultos fueron inhumados dentro de estructuras de paredes de piedra (cámaras funerarias) de diversas formas, utilizando distintos tipos de construcción y ubicación en el interior de los recintos, o colocados directamente en tierra, mientras que los subadultos se depositaron dentro de urnas cerámicas, prácticas éstas habituales en el NOA (Seldes y Gheggi, 2014 para la Quebrada de Humahuaca y Acuto et al., 2011 para el valle Calchaquí).

Hasta el momento no hemos hallado entierros en otros tipos de emplazamientos. En los dos rescates, los restos humanos se encontraron en situaciones de destrucción de los recintos habitacionales. Además, los restos óseos del rescate de 2014 han sufrido acarreo y acciones de movimiento por el agua. No obstante, los huesos han sido hallados en buenas condiciones de conservación, a diferencia de lo notado por los investigadores previos, que destacan haberlos encontrado en estado "pulverulento". Posiblemente esto se debiera a que desarrollaron sus trabajos durante la estación de lluvias, a diferencia de nuestros rescates.

En cuanto a los objetos que acompañaban los entierros, Márquez Miranda destaca el papel simbólico y ceremonial de las palas líticas halladas en los recintos funerarios que, por su morfología, son características de estos valles subterránea e inevitablemente obra de los vivos- contaron en su etapa de construcción con la presencia fundamental de ese artefacto capaz de remover el sedimento"

Arriaga (1999: 21, citado en Chacama, 2003) menciona en relación con los mallquis (cuerpos de los antepasados venerados) que

"... suelen tener con ellos los instrumentos de que ellos usaban en la vida: las mujeres husos y las mazorcas de algodón hilado, y los hombres las tacllas o lampas con que labran el campo, o las armas con que peleaban. En estos Mallquis como también en las huacas, tienen su vajilla para darles de comer y beber, que son mates, y vasos, unos de barro, otros de madera y algunas veces de plata y conchas de la mar".

Este vínculo entre la fertilidad de los campos de laboreo y los ancestros referentes de los ayllus andinos ha sido notado en los trabajos de Allen (2002), Bastien (1995) y Gose (1994). La presencia de estos artefactos se vincula con la conexión existente en los Andes entre los muertos, la fertilidad y la regeneración de la tierra agrícola tal como señala Sillar (1996: 282-283)

"Both the qollqas and the chullpas represent a bond between the people and the land, a continuing commitment to plough, to sow, to fertilize and to offer some of the harvest in sacrifice".

Otras piezas presentes en los contextos funerarios son las cuentas. En los sitios arqueológicos de estos valles orientales se han contabilizado más de 1000 cuentas de distintos materiales, formas y colores, provenientes, principalmente de los entierros (Becerra et al., 2021). A las cuentas se las ha considerado como amuletos para proteger contra enfermedades y otras hechicerías (von Rosen, 1924). Gonzalo Pimentel desde un análisis etnohistórico identifica a las cuentas (huallca) con el concepto de escudo, como elemento de protección, principalmente frente a los seres o divinidades no humanos (Pimentel 2013, en Soto Rodríguez y Pimentel Guzmán, 2020). Estos autores considerarían el uso de las cuentas como "una forma de comunión y reciprocidad entre entidades humanas y no humanas". Sus materiales, con origen sagrado, ya sea en las montañas o en el mar, se usaron como adornos, amuletos o marcadores identitarios (Soto Rodríguez y Pimentel Guzmán 2020, p. 
91). Consideramos que las cuentas pudieron haber sido, además de ornamentos en vida del fallecido, elementos protectores en el nuevo "viaje", que funcionarían como "materiales conectores fundamentales ante diferentes mundos imaginarios o reales" que darían seguridad y buen tránsito (Soto Rodríguez y Pimentel Guzmán, 2020, pp. 91,92). La idea del viaje al morir se ha registrado en un caso etnográfico en Rodeo Colorado, donde la muerte es percibida como un viaje que el individuo comienza en el momento de la muerte, según algunos, o luego de ser enterrado, según otros. "Para el viaje es imprescindible estar bien alimentado, por esta razón junto con el cadáver se entierra comida, igual que cualquiera que se fuese por un tiempo de travesía" (Balzano 1985, 48). Por otro lado, el hallazgo en PVRC de cuentas de sodalita con formación de taranakita se explicaría al estar las cuentas en contacto con los huesos humanos en los entierros, como resultado de procesos post depositacionales sobre esas piezas (Becerra et al., 2021).

Una práctica destacada en los contextos funerarios de estos valles corresponde al doble sellado con barro amasado de colores rojo y amarillo que llega a medir 20 cm de espesor (Márquez Miranda, 1939). Esto significa un tipo de cierre especial de la tumba, así como también un límite o seguridad en el mantenimiento del difunto en ella, mostrando que no habría voluntad de tener acceso continuo con los difuntos, a pesar de vivir con ellos dentro de la vivienda. Esta práctica se diferencia de aquellas postuladas por Acuto et al. (2011) para el período Tardío en el Valle Calchaquí, donde se plantea la posibilidad de apertura de los entierros en vasijas dentro de las viviendas.

El hallazgo de cráneos con deformación tabular oblicua se ha detectado en dos niños y en un adulto en la Colección Márquez Miranda (MLP). Además, en PVRC registramos el entierro en urna de un cráneo de adulto con deformación tabular oblicua, que presentaba como acompañamiento dos cuentas de turquesa y una punta de proyectil morfológicamente similar a las puntas tardías.

Mucho se ha escrito sobre hallazgos de cráneos de adultos en entierros, implicando esta práctica la separación de la cabeza del cuerpo. Generalmente, la cabeza es la parte del cuerpo que más frecuentemente se selecciona para asumir una nueva vida social después de la muerte (Weismantel, 2015). Bastien (1978) menciona que los modernos Aymara mantienen la noción de la cabeza como punto de entrada y salida de la fuerza de la vida. Desde una perspectiva etnográfica y arqueológica, el trabajo de Arnold y Hastorf (2008) ha arrojado luz acerca del uso de la simbología corporal y el uso de las cabezas de enemigos en la configuración del poder a lo largo del tiempo en los Andes. A pesar de que el entierro aislado de cráneos no es una práctica frecuente en los contextos funerarios del NOA, el hallazgo de un cráneo de adulto en urna en PVRC es el primer caso registrado en estos valles orientales y debe ser considerado en el contexto general de las prácticas mortuorias vinculadas con la conservación de partes esqueletales significativas y el rol activo de los muertos sobre los vivos (Bloch y Parry, 1982; Buikstra y Charles, 1999; De Leonardis y Lau, 2004; Parker Pearson, 1993; Sillar, 1992, 1996).

Aunque la ocupación inca en estos valles ha dejado indudables huellas en el paisaje y en el registro material, no parece haber afectado mayormente las prácticas funerarias locales ${ }^{8}$. En Titiconte, considerado un centro administrativo incaico (Presta, 2000; Raffino et al., 1986), la arquitectura difiere de los otros asentamientos, ya que presenta recintos habitacionales de formas cuadradas y rectangulares y recintos subterráneos. Los entierros se construyeron en los ángulos de las paredes de las viviendas, ubicándose también estructuras funerarias circulares en el centro de ellas, detectándose, además, un entierro en uno de los conductos subterráneos. En este sitio no parecen registrarse las capas de barro de colores rojo y/o amarillo que sellan los entierros en PVRC y en otros asentamientos residenciales de estos valles. Sin embargo, las palas líticas forman parte de los entierros en ambos sitios, al igual que en los otros asentamientos. Otra diferencia a destacar entre Titiconte y PVRC son los ajuares funerarios, ya que mientras en el primer sitio son escasos, en PVRC son abundantes y variados y, en gran parte, corresponden a bienes considerados "de prestigio".

Según Alberto Salas (1945, p.98) las prácticas funerarias que Márquez Miranda había registrado en el Departamento de Iruya, en Salta, eran "similares a las humahuacas". También, en Ciénega Grande predominaba la deformación craneana tabular oblicua, al igual que en otros sitios de la Quebrada de Humahuaca. Los grupos de la Quebrada de Humahuaca y de la Puna de Jujuy presentan la mayor proporción de casos de deformación tabular oblicua en el NOA (Cocilovo y Varela, 2010). La creciente importancia de la deformación tabular oblicua en el Período de Desarrollos Regionales en la Quebrada de Humahuaca es destacada por Seldes y Botta (2014), considerando que no ha sido registrada en la región durante el Período Formativo. La aparición de esta variante y su alta frecuencia pudo ser resultado del aumento del intercambio interregional relacionado con el auge del caravaneo en los Andes Circumpuneños. Para Seldes (2012) esta circunstancia pudo haber llevado a la gente a adoptar nuevas prácticas de identidad.

Al igual que en estos valles orientales, en algunos sitios de la Quebrada de Humahuaca no son claras las modificaciones que pudo haber impuesto la ocupación incaica en los contextos funerarios. En La Huerta, Raffino y colaboradores (1993, pp. 89,90), no lograron diferenciar una arquitectura funeraria Humahuaca o local de otra presuntamente Inca. "Ambos tipos mayoritarios de cámaras, cuadrangulares y circulares

8 Una idea similar fue planteada por Amuedo y Kergaravat (2009) para el Valle Calchaquí norte durante el momento Inca. 
con bóveda en saledizo, aparecen y coexisten dentro de los edificios cuzqueños como en el resto del área intramuros". Su diagnóstico -al menos en ese sitio- remite a la presencia o no de piezas o ajuares pertenecientes al componente Humahuaca, al Humahuaca-Inca, e inclusive al Humahuaca histórico.

\section{A modo de cierre}

Este trabajo es una primera aproximación a las formas de tratamiento de los muertos que se llevaron a cabo en los valles orientales de Iruya, Bacoya y Nazareno, en el norte de Salta. Lamentablemente las investigaciones arqueológicas de los años 1930 se concentraron en ciertos aspectos de las prácticas funerarias dejando de lado otras tantas, donde no se incluyó el estudio de los restos humanos. Sin embargo, gracias a esos datos, generalmente aislados e insuficientes, podemos comenzar a analizar en forma preliminar las relaciones de las poblaciones que ocuparon estos valles con sus muertos a través del tiempo. Hasta el momento sólo hemos podido aportar al tema a través de dos rescates, uno de los cuales ha indicado una nueva e interesante práctica funeraria no común en el NOA, como es el entierro en urna de un cráneo de adulto con deformación tabular oblicua, con posible evidencia de trauma. Mientras que en el otro rescate fue posible datar las primeras ocupaciones de PVRC con un fechado sobre los restos humanos, además de registrar datos sobre un par de individuos que fueron allí enterrados. Dos fechados en otro sector del sitio corroboran la ocupación temprana de PVRC.

A pesar del limitado número de dataciones radiocarbónicas, la evidencia disponible permite sostener que las ocupaciones en PVRC se extendieron entre ca. 400 D.C. y el siglo XV. Mientras que en otros asentamientos ciertos indicios materiales indicarían que las mismas se prolongan hasta momentos hispano-indígena. Aún se requieren muchas investigaciones para entender como fueron las interacciones entre los vivos y los muertos en estos valles orientales a lo largo del tiempo, pero hemos iniciado esa búsqueda.

\section{Trabajo con las comunidades y devolución de los restos humanos}

Los trabajos con las comunidades en las que llevamos a cabo nuestras investigaciones arqueológicas se basan en respetar los acuerdos realizados con las mismas, así como los permisos otorgados para cada actividad, por lo cual los tiempos no siempre corresponden a los que la Academia exige.

Tal como habíamos prometido a las comunidades Kolla de Rodeo Colorado y Abra del Sauce, una vez realizados los estudios y análisis sobre los restos humanos, resultado del rescate de 2014 en PVRC, los mismos fueron devueltos a ésta última comunidad, la más cercana al sitio arqueológico. Para ello, la Lic. Norma Pérez, conservadora del Instituto de Arqueología (UBA) los acondicionó para el traslado a su lugar de origen. En abril de 2016, junto con la Dra. Becerra, hicimos la devolución de los restos humanos a la comunidad de Abra del Sauce participando el Presidente del Centro Kolla Unido de Abra del Sauce y Rodeo Colorado, Sr. Angel Mendoza y otros miembros de la comunidad, firmándose un Acta sobre dicho evento.

Buenos Aires y La Rioja, 10 de Mayo de 2021

\section{Agradecimientos}

A los miembros de las comunidades Abra del Sauce y Rodeo Colorado, al Centro Kolla de ambas comunidades, a Mariette Albeck, María Florencia Becerra, Norma Pérez, Mariana Rosenbusch, María Vardé, Susana Salceda, Julio Avalos, Luis Borrero. A las autoridades y personal del Museo de La Plata y del Museo Etnográfico de Buenos Aires. A los evaluadores por sus útiles sugerencias.

\section{Bibliografía}

Acuto, F., Kergaravat, M. y Amuedo, C. (2011). Experiencia de la muerte y la representación de las personas en las prácticas funerarias del valle Calchaquí Norte. Comechingonia, 14 (1), 23-54. DOI:10.37603/2250.7728. v14.n1.17891.

Aláez García, A. (2001). Duelo Andino: sabiduría y elaboración de la muerte en los rituales mortuorios. Chungara. Revista de Antropología Chilena, 33 (2), 173178.DOI: 10.4067/S0717-73562001000200002.

Allen, C. (2002) [1988]. The Hold Life Has: Coca and Cultural Identity in an Andean Community. Smithsonian Institution Press: Washington, D. C

Amuedo, C. y Kergaravat, M. (2009). Las transformaciones en las prácticas culturales de los colonizados: las prácticas mortuorias bajo el dominio incaico en el Valle Calchaquí Norte (Noa). Actas del XVIII Congreso Nacional de Arqueología Chilena: 33-42.

Arnold, D. y Hastorf, C. (2008). Heads of State. Icons, power and politics in the ancient and modern Andes. Left Coast Press: California.

Arriaga, P.J. 1999 [1621]. La extirpación de las idolatrías en Pirú. Centro de Estudios Regionales Andinos "Bartolomé de Las Casas": Cuzco.

Avila, F. (2011). El efecto de lo bello. Valores estéticos y práctica social. El estilo alfarero Yavi-Chicha. S. XV a XVI (Tesis Doctoral inédita). Facultad de Filosofía y Letras, Universidad de Buenos Aires: Buenos Aires.

Baffi, I. y Seldes, V. (2012). La mujer en el registro 
bioarqueológico y su visibilidad en los contextos funerarios. Comechingonia 16 (1), 53-70.

Balzano, S. (1985). "Ella no estaba sola". Análisis de un caso de suicidio en Rodeo Colorado. Scripta Ethnologica IX, 37-52.

Bascopé Caero, V. (2001). El sentido de la muerte en la cosmovisión andina: el caso de los valles andinos de Cochabamba. Chungara. Revista de Antropología Chilena, 33 (2), 271-277. DOI: 10.4067/S0717.

Bastien, J. W. (1978). Mountain of the Condor: Metaphor and Ritual in an Andean Ayllu. Waverly Press: Illinois.

Bastien, J. W. (1995). The mountain/body metaphor expressed in a Kaatan funeral. En T. Dillehay (Ed.), Tombs for the living: Andean mortuary practices (pp. 355-378), Dumbarton Oaks: Washington D.C

Becerra, M.F., Ventura, B., Solá, P., Rosenbusch, M., Cozzi,G. y Romano, A. (2021). Arqueomineralogía de cuentas de los valles orientales del norte de Salta, Argentina. Boletín del Museo Chileno de Arte precolombino 26 (1), 93-112.

Bennett, W.C. (1948a).The North. En Northwest Argentine Archeology. (pp. 19-43).Yale University Publications in Anthropology: New Haven.

Bennett, W.C. (1948b). Interrelations. En Northwest Argentine Archeology. (pp. 140-150).Yale University Publications in Anthropology: New Haven.

Bloch, M. y Parry, J. (1982). Death and the Regeneration of Life. Cambridge University Press: Cambridge.

Bordach, M. A. (2006). Interacciones étnicas e indicadores de desigualdad social en el cementerio de La Falda (SJTIL43) de Tilcara, Jujuy. Estudios Atacameños 31, 115-128.

Bronk Ramsey, C. (2009). Bayesian analysis of radiocarbon dates. Radiocarbon 51, 337-360.

Buikstra, J.E. (1995). Tombs for the living... or... for the Dead: The Osmore Ancestors. En T.D. Dillehay (Ed.), Tombs for the living: Andean mortuary practices, pp. 229280. Dumbarton Oaks Research Library and Collection: Washington D.C.

Buikstra, J.E.y Ubelaker, D.H. (1994). Standards for data collection from human skeletal remains. Proceedings of a Seminar at the Field Museum of Natural History. Organizado por J. Haas. Arkansas Archaeological Survey Research Series No. 44.

Buikstra, J. E.y Charles, D. (1999).Centering the Ancestors:
Cemeteries, Mounds and Sacred Landscapes of the Ancient North America Midcontinent. En W. Ashmore y A.B. Knapp (Eds.), Archaeologies of Landscape: Contemporary Perspectives (pp.201-228). Blackwell: Oxford.

Casanova, E. (1930). Excursión arqueológica al Cerro Morado, Notas del Museo Etnográfico 3, 5-40: Buenos Aires.

Chacama, J. (2003). Identidad espiritual y organización social en los Andes. Revista de Historia Indígena 7: 137158

Cocilovo, J. y Costa-Junqueira, M.A. (2001). La deformación artificial en el Período Arcaico de Arica. Latin American Antiquity 12, 203-214.

Cocilovo, J. y Varela, H. (2010). La distribución de la deformación artificial de cráneo en el área andina centro sur. Relaciones de la Sociedad Argentina de Antropología $\mathrm{XXXV}$, 41-68.

Debenedetti, S. y Casanova, E. (1933-35). Titiconte, Publicaciones del Museo Antropológico y Etnográfico, Serie A, III, 7-35.

De Leonardis, L. y Lau G. F. (2004). Life, death and ancestors. En H. Silverman (Ed.), Andean Archaeology, (pp. 77-115). Blackwell Publishing: Malden.

Dillehay, T. (1995). (Ed.). Tombs for the living: Andean mortuary practices. Dumbarton Oaks Research Library and Collection: Washington D.C.

Gheggi, M. S. y Seldes, V. (2012). Evidencias bioarqueológicas de conflicto $c a$. 1000-1432 AD en la Quebrada de Humahuaca y el Valle Calchaquí. Intersecciones en Antropología 13, 103-115.

Gheggi, M. S., Williams, V. y Cremonte, M.B. (2018). The Impact of the Inca Empire in Northwest Argentina: Assessment of health status and food consumption at Esquina de Huajra (Quebrada de Humahuaca, Argentina). International Journal Osteoarchaeology 2018, 1-11.

Granda, P. (2011). Paisaje y arquitectura en los valles orientales del norte de Salta (Argentina) (Tesis de Licenciatura inédita). Facultad de Filosofía y Letras, Universidad de Buenos Aires: Buenos Aires.

Gose, P. (1994). Deathly Waters and Hungry Mountains: Agrarian Ritual and Class Formation in an Andean Town, En M. Lambek (Ed.), Anthropological Horizons (N.4). University of Toronto Press: Toronto.

Haber, A. y Gastaldi, M. (2006). Vida con palas. Antípoda 2, 275-302. 
Hogg,A.; Heaton,T.; Hua,Q. ;Palmer, J.;Turney,C.; Southon, J.; Bayliss,A.; Blackwell,P.; Boswijk,G.; Bronk Ramsey,C.;Petchey,F.; Reimer,P. y Wacker,L. (2020). SHCal20 Southern Hemisphere calibration 0-55,000 years cal BP, Radiocarbon 62.

Killian Galván V. (2018). Models for paleodietary research: three case-studies from arid and semiarid environments in Northwest Argentina. Journal of Archaeological Science. Report 18: 608-616.

Killian Galván V.; Cortéz, L.T. y Rabuffetti, N. (2021). Composition of prehispanic diets from stable isotope analysis in human remains of Southern Calchaqui valleys, Northwest Argentina (3600-1300 BP). Latin American Antiquity 1-18. DOI: 10.1017/laq.2020.101.

Madrazo, G. y Ottonello, M. (1966).Tipos de instalación prehistóricos en la región de la Puna y su borde. Monografías 1, Museo Municipal de Olavarría: Olavarría.

Márquez Miranda, F. (1934). El "Pucará" del pie de la Cuesta de Colanzulí. Nota preliminar sobre un nuevo yacimiento arqueológico salteño. Notas preliminares del Museo de La Plata, Tomo II, 259-269.

Márquez Miranda, F. (1937). Arquitectura aborigen en la provincia de Salta. Relaciones de la Sociedad Argentina de Antropología 1, 141-186.

Márquez Miranda, F. (1939). Cuatro viajes de estudio al más remoto Noroeste argentino. Revista del Museo de La Plata, Tomo I, Antropología 6, 93-243: La Plata.

Márquez Miranda, F. (1941). La arqueología del este de la Quebrada de Humahuaca (frontera argentinoboliviana) a través de nuevas investigaciones. Actas del XXVII Congreso Internacional de Americanistas, vol. 1, 211-237: Lima.

Mendonça, O.; Bordach, M.A. y Arrieta, M. (2012). El comportamiento mortuorio en Til 43 y RCH 21 del Tardío al Hispano -Indígena: Continuidades, transformaciones y rupturas materiales y simbólicas. Perspectiva regional. Pacarina 7, 67-82: Jujuy.

Oliveto, L. G. y Ventura, B.N. (2017). Final de la jornada al Chaco de Ledesma Valderrama en 1631. Análisis y nuevas perspectivas a partir de documentación inédita, Relaciones de la Sociedad Argentina de Antropología XLII (2), 257-280.

Ortíz, G. y Seldes, V. (2007). Alcances y limitaciones para el estudio de restos óseos arqueológicos de la región subandina de Jujuy (área del río San Francisco). Cuadernos 32, 255-268. Facultad de Humanidades y Ciencias Sociales, Universidad Nacional de Jujuy: San
Salvador de Jujuy.

Parker Pearson, M. (1993). The Powerful Dead: Archaeological Relationship Between the Living and the Death. Cambridge Archaeological Journal 3, 203-229.

Parker Pearson, M. (1999). The Archaeology of Death and Burial. Texas University Press: Texas.

Pérez, J. A. (1968). Subárea de Humahuaca. Actas y Memorias. XXXVII Congreso Internacional de Americanistas 1966, Vol. II, 273-293: Buenos Aires.

Pommeroy, E. y Stock, J. (2012). Estimation of Stature and Body Mass From the Skeleton Among Coastal and Mid-Altitude Andean Populations. American Journal of Physical Anthropology 147, 264-279.

Presta, A. M. (2000). Encomienda, Familia y negocios en Charcas colonial. Los encomenderos de La Plata 15501600, IEP-BCRP: Lima.

Raffino, R. (1993). Al Este del Paraíso. En R. Raffino (Ed.), Inka. Arqueología, Historia y Urbanismo del Altiplano Andino (pp. 213-234). Ediciones Corregidor: Buenos Aires.

Raffino, R.; Alvis, R.; Olivera, D. y Palma, J. (1986). La instalación Inka en la sección andina meridional de Bolivia y extremo boreal de Argentina, Comechingonia, volumen especial, 63-131.

Raffino, R.y Palma, J. (1993).Los Artefactos. En R. Raffino (Ed.), Inka. Arqueología, Historia y Urbanismo del Altiplano Andino (pp. 93-129). Ediciones Corregidor: Buenos Aires.

Raffino, R.; García Montes, V. y Manso, A. (1993). La funebria de La Huerta. En R. Raffino (Ed.). Inka. Arqueología, Historia y Urbanismo del Altiplano Andino (pp.77-92). Ediciones Corregidor: Buenos Aires.

Rakita, G.F.M. (2001). Social complexity, religious organization, and mortuary ritual in the Casas Grandes region of Chihuahua, Mexico. P.h.D. dissertation, University of New Mexico: Albuquerque.

Rosen, E. von (1924). Ethnographical Research Work during the Swedish Chaco-Cordillera Expedition 19011902. A. Bonniers Boktryckeri: Stockholm.

Salas, A. M. (1945). El Antigal de Ciénega Grande (Quebrada de Humahuaca, Provincia de Jujuy), Publicaciones del Museo Etnográfico de la Facultad de Filosofía y Letras, Serie A, V: Buenos Aires.

Schobinger, J. (1966). La "momia" del Cerro El Toro. Investigaciones arqueológicas en la cordillera de la 
provincia de San Juan (República Argentina). Anales de Arqueología y Etnología,Suplemento al tomo XXI: Mendoza.

Seldes, V. (2012). Hacia una bioarqueología social. La Quebrada de Humahuaca en perspectiva histórica. Academia Española editorial: Saarbrucken.

Seldes, V. y Botta, F.N. (2014).Violence indicators in Quebrada de Humahuaca, Jujuy, Argentina: The Regional Development Period from a regional perspective. Anthropological Review 77 (1), 87-109.

Seldes V. y Gheggi, M.S. (Eds.). (2014). Antropología biológica y estudios del comportamiento mortuorio de los pueblos prehispánicos del Noroeste argentino. Editorial Azara: Buenos Aires.

Shimada I. y Fitzsimmons, J. (Eds.). (2015). Living with the dead in the Andes. The University of Arizona Press: Tucson.

Sillar, B. (1992). The Social Life of the Andean Dead. Archaeological Review from Cambridge 11(1), 107-23.

(1996). The Dead and the Drying: Techniques for Transforming People and Things in the Andes. Journal of Material Culture, 1, 259-289.

Soto Rodríguez, C., y Pimentel Guzmán, G. (2020). Ch'allando cuentas para un buen viaje: objetos perforados prehispánicos en senderos del desierto de Atacama, Chile. Praxis Arqueológica, 1(1), 76-97. https://doi. org/10.11565/pa.v1i1.9

Steele G. y McKern, T.W. (1969).A method for assessment of maximum bone length and living stature from fragmentary long bones. American Journal of Physical Anthropology 31, 215-218.

Steele D. G. y Bramblett, C.A. (2000). The anatomy and biology of the human skeleton. Texas University Press: Texas.

Tarragó, M. (1984). El contacto hispano- indígena. La Provincia de Chicoana. Runa 14, 143-185.

Tarragó, M. (1989). Contribuciones al conocimiento arqueológico de San Pedro de Atacama en relación con los otros pueblos puneños, en especial el sector septentrional del Valle Calchaquí (Tesis Doctoral inédita), Universidad Nacional de Rosario: Rosario.

Ventura, B. N. (1999). Arqueología de los valles orientales a las Serranías de Zenta y Santa Victoria, Salta (Tesis Doctoral inédita), Facultad de Filosofía y Letras, Universidad de Buenos Aires: Buenos Aires.
Ventura, B. N. (2011). La colección Márquez Miranda. Análisis del material arqueológico proveniente de los valles orientales del norte de Salta (Argentina). Trabajo presentado en el II Simposio Internacional de Colecciones de Museos e Investigación "Patrimonio, diversidad cultural en inclusión social", Salta: Publicado en CD por el Simposio, pp.1-10.

Ventura, B. N. (2016). Esferas de interacción y circulación de bienes y poblaciones en un sector de la frontera sur oriental del Tawantinsuyu. Los valles orientales del norte de Salta, Argentina. En S. Alconini (Ed.), Entre la vertiente tropical y los valles. Sociedades regionales e interacción prehispánicas en los Andes Centro-Sur (pp. 301-318). Editorial Plural: La Paz.

Ventura, B. N. (2017). La ocupación inca en los valles orientales del norte de Salta (Argentina). En B. Ventura; G.Ortíz y M.B.Cremonte (Eds.), Arqueología de la vertiente oriental Surandina. Interacción macro-regional, materialidades, economía y ritualidad (pp. 171-204). Sociedad Argentina de Antropología: Buenos Aires.

Ventura, B. N. (2019).Chipanas y orejones en la frontera oriental del Tawantinsuyu. Una propuesta desde la arqueología y la etnohistoria para los valles orientales del norte de Salta, Argentina. Memoria Americana. Cuadernos de Etnohistoria 27 (1), 11-30: Buenos Aires.

Ventura, B. y Scambato, A.C. (2013). La metalurgia de los valles orientales del norte de Salta, Argentina. Boletín del Museo Chileno de Arte Precolombino 18 (1), 85-106: Santiago.

Ventura, B. y Oliveto, L.G. (2014). "Resabios de otros tiempos". Dominio incaico en los valles orientales del norte de Salta, Argentina. Bulletin de I'Institut Francais d'Etudes Andines 43(2), 285-310: Lima.

Ventura, B. y Becerra, M.F. (2018). Los valles orientales de Salta (Argentina)durante el dominio inca y la Colonia temprana. Territorialidad, diversidad poblacional, interacción e intercambio con la Puna de Jujuy. Una mirada desde la arqueología y la etnohistoria. En M.A. Muñoz (Ed.), Interpretando huellas. Arqueología, etnohistoria y etnografía de los Andes y sus Tierras Bajas (pp. 327-347). Editorial Kipus: Cochabamba.

Verano J. (2008). Trophy Head-Taking and Human Sacrifice in Andean South America. En H. Silverman y W.Isbell (Eds.) Handbook of South American Archaeology (pp. 1047-1062). Springer Press: New York.

Weismantel, M. (2015). Many heads are better than one. Mortuary Practice and Ceramic Art in Moche Society. En I.Shimada y J. Fitzsimmons (Eds.) Living with the dead in the Andes (pp. 76-100).The University of Arizona Press: Tucson. 
B. N. Ventura y M. S. Gheggi | Revista del Museo de Antropología 14 (3): 87-102 | 2021 DOI: http://doi.org/10.31048/1852.4826.v14.n3.32996 